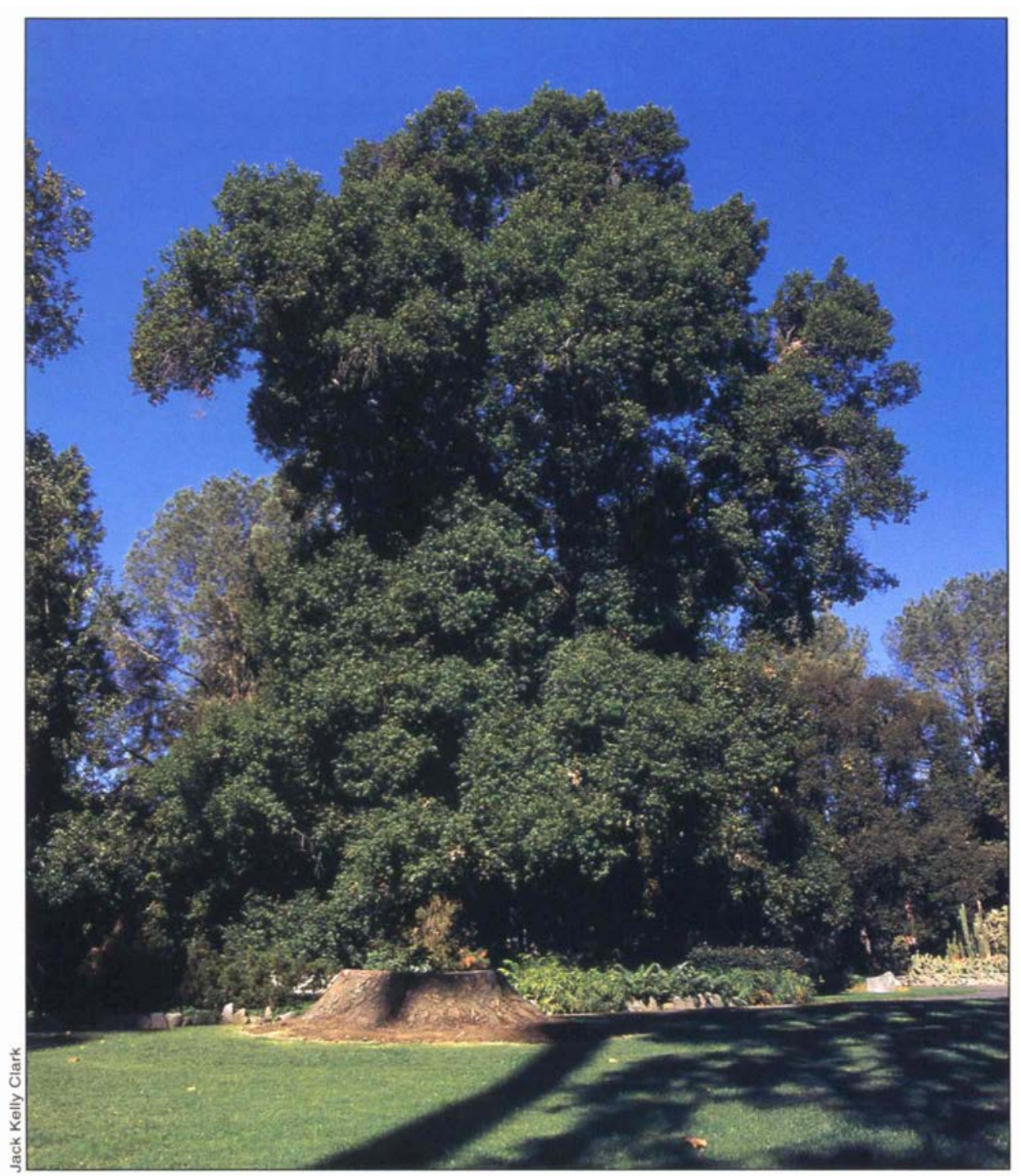

\title{
Obscure scale declines after parasitic wasp introduced
}

\author{
Lester E. Ehler
}

Obscure scale, a pest of oak and pecan trees, was found in Sacramento's Capitol Park in 1962. By 1980 the scale was threatening the park's oaks. Red oaks seemed especially susceptible. In 1987-88 the imported parasite Encarsia aurantii was released to control the scale; the parasite's establishment was confirmed in 1990. By the end of 1996, scale infestations on both native and introduced oaks in the park were reduced to levels approaching complete biological control.
Obscure scale is an armored scale (family Diaspididae) that is native to the eastern half of the United States. In its native range, the scale is primarily associated with tree hosts in the genera Quercus, Carya and Castanea. Obscure scale is a common pest of urban oaks, but it is seldom a problem in natural stands. It is also a minor pest of pecan trees. There have been three documented introductions of obscure scale in California. The first was detected on pecans and English walnuts in Los Angeles County in 1933; the second was detected on pecans in San Diego County in 1934. Both infesta-

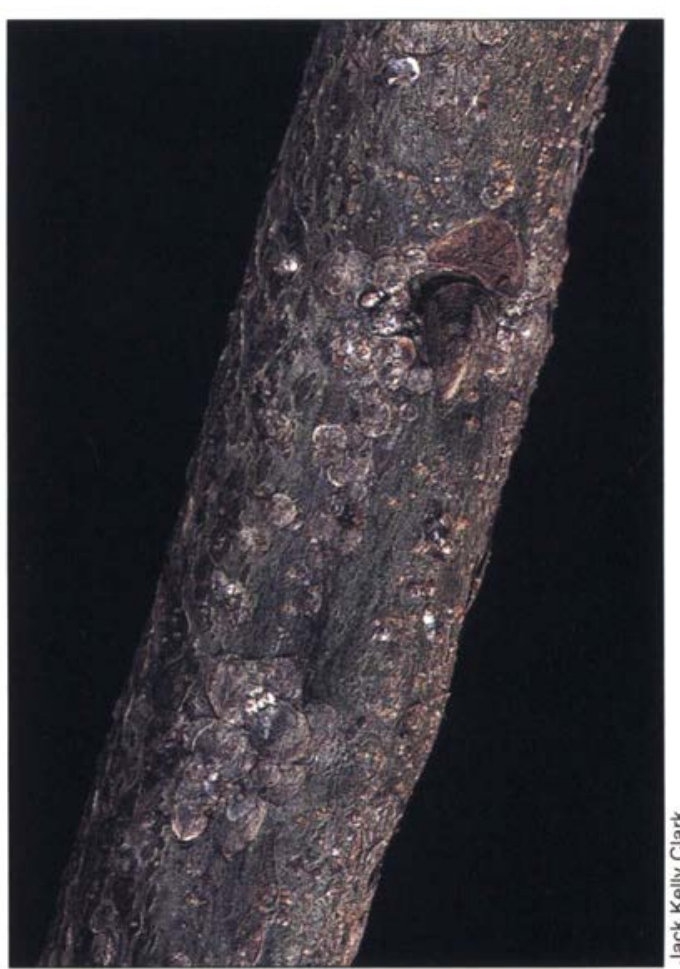

Sacramento's Capitol Park contains a mixture of native and introduced oaks that would be at risk if obscure scale were to spread. tions were eradicated. The third infestation was discovered on oaks in Capitol Park in Sacramento in 1962. In Sacramento, however, eradication efforts were not successful. By 1980 this infestation had intensified, threatening both native and introduced oaks in the park. It then became a target for classical biological control.

\section{Obscure scale in Capitol Park}

Capitol Park contains a mixture of native and introduced oaks, along with a variety of other trees. A number of the North American oaks are infested with obscure scale (Melanaspis 
obscura [Comstock]) (table 1). Red oaks seem especially susceptible. Among oaks that are native to eastern North America, northern red oak, pin oak and willow oak appear to be good. hosts, and this is consistent with our observations in the eastern United States. Among oaks that are native to western North America, coast live oak and interior live oak appear to be good hosts, and valley oak is evidently a poor host. Thus, if obscure scale were to spread throughout the state, both coast live oak and interior live oak might be at considerable risk. The three Old World oaks in the park are evidently not infested. At present, the Sacramento infestation is apparently restricted to Capitol Park.

The life history of obscure scale in Capitol Park is similar to that observed in its native range. There is only one generation per year. Females develop through three instars, compared to five in males. Second-instar males and females overwinter, and by mid-April both sexes have usually developed into mature scales. Males emerge during April and May and mate with the sessile females. Gravid females begin laying eggs in late June; eggs hatch into crawlers (first-instar scales) that eventually settle and begin feeding. Peak crawler production occurs in midsummer. By mid-December, most scales are in the second instar. Phenology of the various stages varies somewhat with host-tree species.

\section{Classical biological control}

We searched for natural enemies of obscure scale among pecan trees (Carya illinoensis [Wagenheim] $\mathrm{K}$. Koch) in southern Texas from 1983 through 1987. Scale-infested twigs were collected in Austin (Travis County), College Station (Brazos County) and Temple (Bell County); these were returned to the quarantine laboratory at Davis and held for emergence of parasites. We recovered 11 species of parasites, including both primary parasites, which develop on the scale, and secondary, which develop on the primary parasites.

Among the primary parasites, the aphelinid Encarsia aurantii (Howard) was chosen for release in California. This decision was based on the abundance of this species in southern Texas, its egg load at emergence (about three times the lifetime fecun- dity of obscure scale) and its thelyotokous mode of parthenogenesis (females beget females; males are rarely encountered). This species cleared quarantine in 1987, and a few females were released in the fall. The remaining females were committed to a mass-rearing program utilizing oleander scale (Aspidiotus nerii Bouche) as an insectary host. In the summer and fall of 1988, more than 11,000 females were reared and released in Capitol Park. In most cases, releases were made on the oak trees that were most severely infested with obscure scale. Twig samples taken in June 1990 revealed that the parasite was firmly established.

Postrelease evaluation of scale and parasite populations was initiated the following year. Because all of the infested oaks were large "specimen" trees, including some of historic significance, it was not permissible to remove twig samples on a regular basis throughout the course of the study.

Therefore most of the evaluation was based on capture of scale crawlers and adult parasites on sticky traps.

In spring 1991, five yellow card traps (Number 611 [10 x $15 \mathrm{~cm}$ ], Phero Tech, Delta, BC, Canada) were hung in each of five release trees (two northern red oaks, one pin oak, one coast live oak and one interior live oak). We retrieved and replaced traps at regular intervals (usually 2 weeks) throughout the summer and into fall. Traps captured adult parasites, scale crawlers and male scales. In subsequent years, trapping was initiated in April, just prior to male emergence, and was terminated by mid-October.

Only counts of crawlers and parasites are summarized here. These counts cannot be translated into actual densities on release trees, and should instead be considered as indices of insect abundance. Unfortunately, the coast live oak that was being sampled became diseased and was removed in fall 1991. Because crawlers were inadequately sampled in 1991, the evaluation that follows is based on four trees from 1992 through 1996.

Emergence of parasites coincided with initial production of scale crawl- 


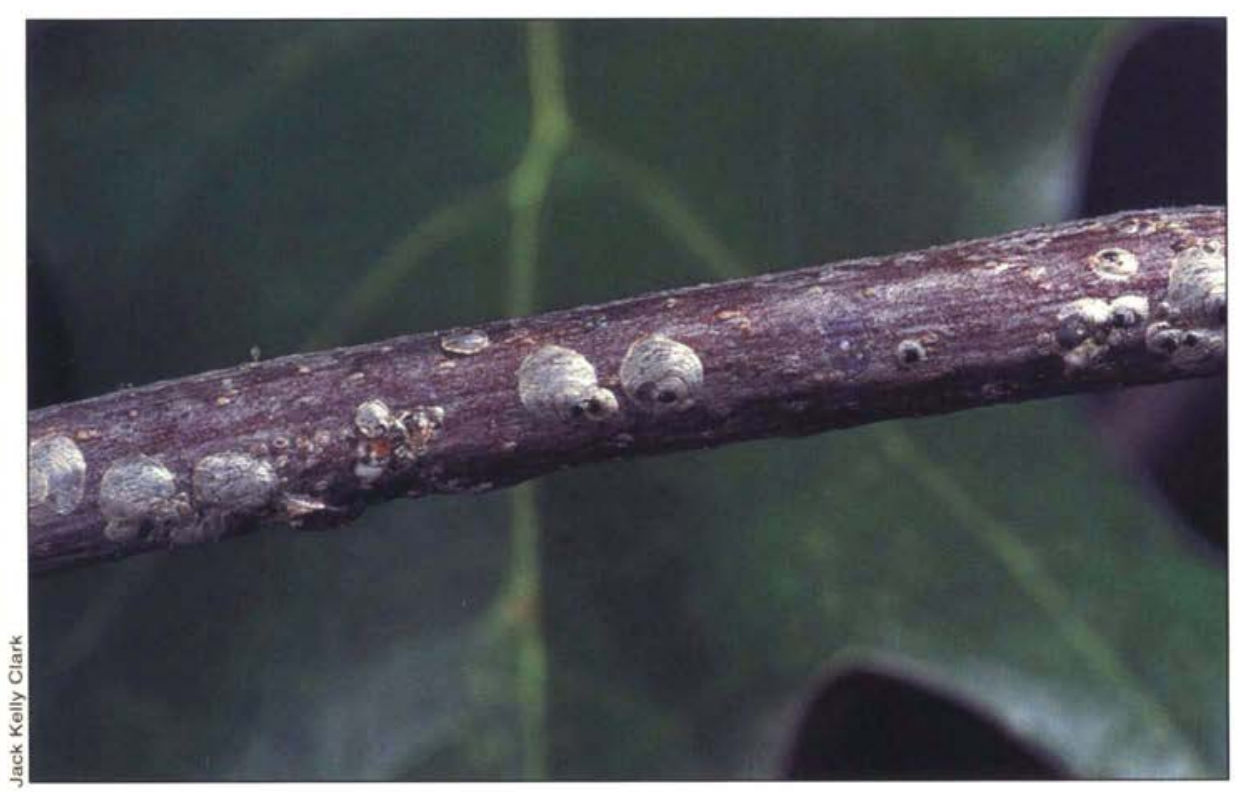

ers (figs. 1 - 4). The emergence period of the parasite was relatively short and discrete, indicating a single generation to each generation of the scale host. However, production of scale crawlers continued into late summer and early fall; this may provide an important refuge for the scale population. Female parasites are short-lived and oviposit in newly settled scales. The larvae develop as endoparasites over the next several months, killing the second-instar host, and pupate by the following spring. Adults chew a characteristic emergence hole in the scale covering and emerge in mid- to late July. Thus the impact of the parasite in a given year will be related to the abundance of females (compare trap catch) during the previous year. Of the hundreds of parasites observed on sticky cards since 1991, all were female.

On each of the four trees targeted for evaluation, there was an increase in cumulative trap capture of parasites and a concomitant decline in cumulative capture of scale crawlers from 1992 through 1995. For the most severely infested northern red oak, the number of parasites captured increased by about 19 times by the end of 1995 and then declined; capture of scale crawlers declined by about threefold by the end of 1996 (fig. 1). This tree was apparently subjected to considerable insecticide drift from treat- ment of a nearby elm, which may have lessened the impact of the parasite in 1992 and 1993. However, by the end of 1995 the parasite population had clearly recovered from any such chemical disturbance.

On the interior live oak, the cumulative trap catch for parasites doubled

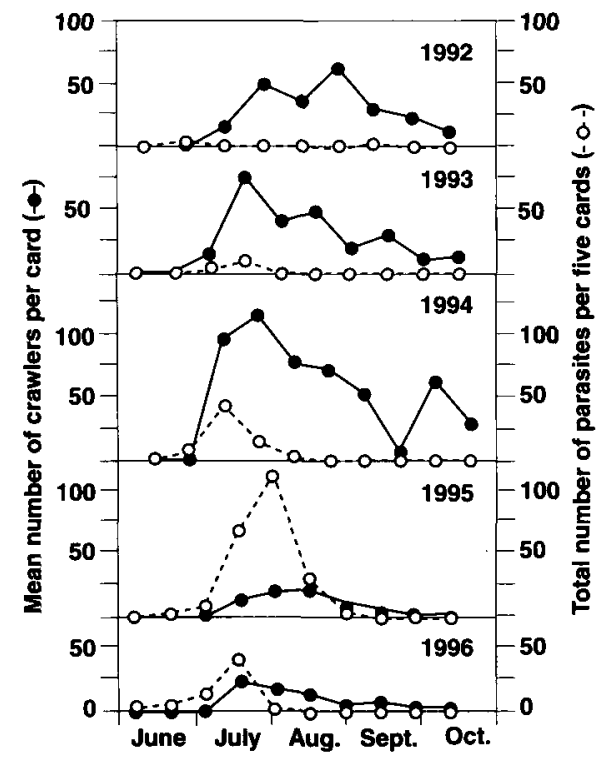

Fig. 1. Trap catch of scale crawlers and adult parasites on a northern red oak in Capitol Park. Each point represents total number captured during indicated interval, plotted at midinterval. This oak was apparently subjected to insecticide drift, which may have reduced numbers of the parasite in 1992 and 1993.

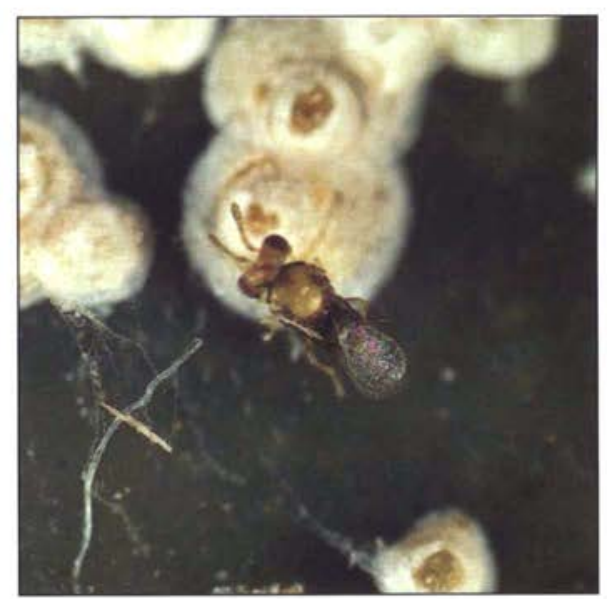

A E. aurantii parasitizing an oleander scale in the laboratory.

Emergence hole in scale cover made by adult $E$. aurantii.

from 1992 through 1995 and then declined; in contrast, trap catch for crawlers had declined about 30 -fold by the end of 1996 (fig. 2).

On the pin oak, the cumulative trap catch of parasites increased by about 30-fold from 1992 through 1995 and declined in 1996. Trap capture of

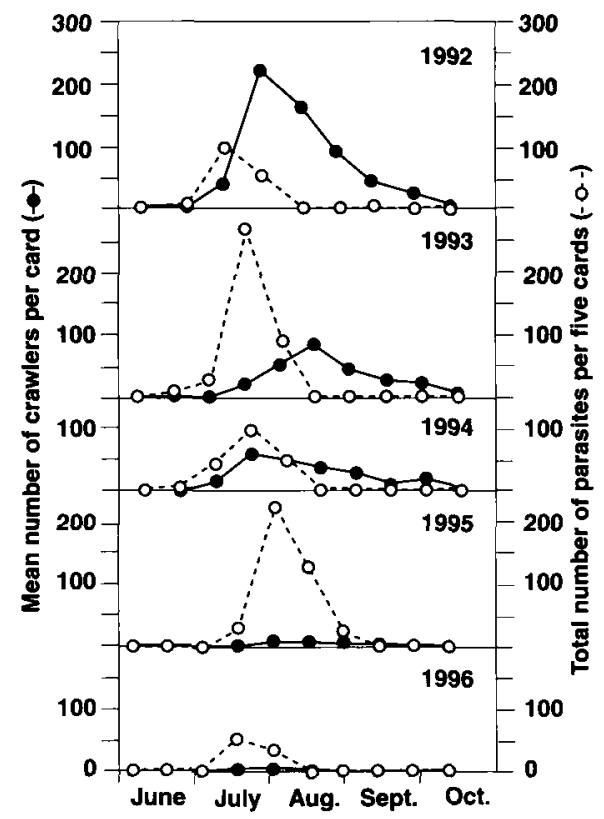

Fig. 2. Trap catch of scale crawlers and adult parasites on an interior live oak in Capitol Park. Each point represents total number captured during indicated interval, plotted at midinterval. 


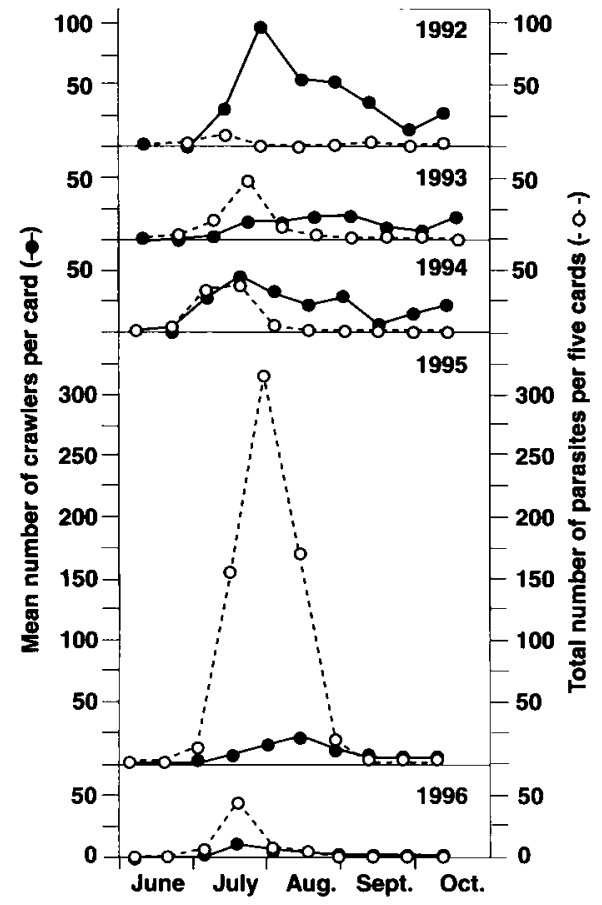

Fig. 3. Trap catch of scale crawlers and adult parasites on a pin oak in Capitol Park. Each point represents total number captured during indicated interval, plotted at midinterval.

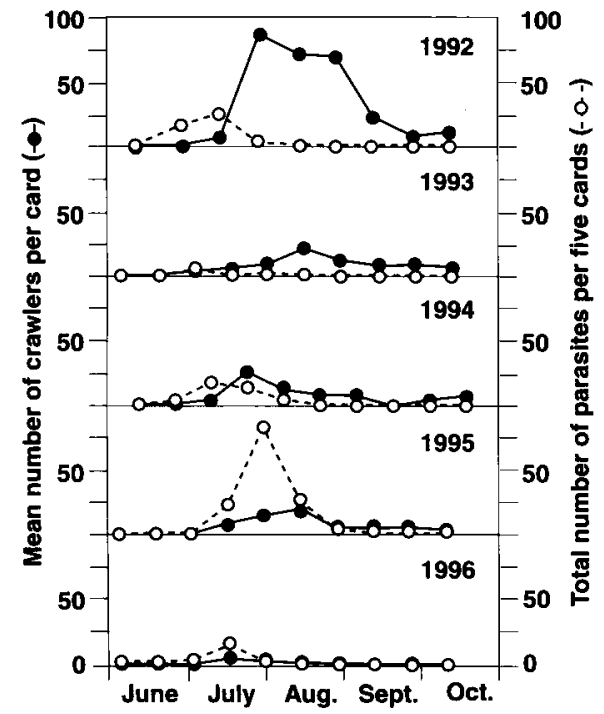

Fig. 4. Trap catch of scale crawlers and adult parasites on a second northern red oak in Capitol Park. Each point represents total number captured during indicated interval, plotted at midinterval. crawlers was reduced about 11-fold by the end of 1996 (fig. 3).

Similar patterns were observed on the second northern red oak: cumulative trap capture of parasites doubled from 1992 through 1995 before declining in 1996, compared to a reduction in crawler capture of about 16-fold by the end of 1996 (fig. 4).

Overall, cumulative trap capture of parasites increased about fivefold by 1995 compared to a reduction in cumulative crawler capture of about 10fold by the end of 1996. Crawler-toparasite ratio also declined, from about 26 in 1992 to about 3 in 1996. During peak emergence of parasites and crawlers in 1995, card traps hung in four additional trees (one coast live oak and three northern red oaks) revealed that during this period (July 10 to Aug. 7), cumulative trap capture of parasites was either about equal to or exceeded that of crawlers on three of the trees, indicating that the parasite had spread well beyond the original release trees. It was also well established on the fourth tree sampled.

A limited number of twig samples taken from the interior live oak on June 29, $1994(\mathrm{n}=128)$ and May 14, 1997 ( $n=66)$ provided additional evidence of the impact of the parasite. Each twig was about 6 to 8 inches (15 to $20 \mathrm{~cm}$ ) long and represented growth from the current year plus the previous 2 to 3 years. In 1994, mean number of scales per twig was 4.2 (range 0 to 32); $82 \%$ of the twigs were infested and $38.1 \%$ of the scales were parasitized by E. aurantii. By 1997, scale density was reduced by over 20 times (mean of 0.18 scale per twig, range 0 to 3 ); only $10.6 \%$ of the twigs were infested; and of the 12 scales detected, 10 $(83.3 \%)$ were parasitized.

Cumulative trap catches for both crawlers and parasites in 1997 were similar to those in 1996, indicating that the populations are beginning to stabilize at relatively low levels.

\section{Further monitoring required}

Nine years after the release of E. aurantii, its population has increased greatly and spread throughout Capitol Park, while the obscure scale population has been reduced to levels approaching complete biological control. Future research will emphasize continued monitoring of both scale and parasite populations, plus experimental demonstration of the role of $E$. aurantii in the decline of obscure scale. If and when new infestations of obscure scale are discovered in California, on either oak or pecan, release of E. aurantii should be a priority, especially when eradication of the infestation is not feasible.

In eastern North America, obscure scale seems to be a good target for augmentative release of $E$. aurantii, particularly on street trees, in parks and in other disturbed areas. Mass production of the parasite on oleander scale is not particularly difficult and should be relatively inexpensive for a commercial insectary, a municipality or a government agency.

Because obscure scale has only one generation per year (univoltine), some monitoring will be required to ensure that releases of the parasite coincide with first-instar scales. Because $E$. aurantii is also univoltine, the length of time required to achieve satisfactory control, in either classical or augmentative biological control, may be extended. However, this varies with the initial scale density and release rate. Annual releases of the parasite could also accelerate the process.

L.E. Ehler is Professor and Entomologist, Department of Entomology, UC Davis.

\section{Further reading}

Ehler LE. 1995. Biological control of obscure scale (Homoptera:

Diaspididae) in California: an experimental approach. Env Ent 24:779-95. 